\title{
THE EFFECTS OF ACUTE HYPOXIA ON THE SYSTEMIC VENOUS AND ARTERIAL SYSTEMS AND ON MYOCARDIAL CONTRACTILE FORCE
}

\author{
By RICHARD L. KAHLER, ALLAN GOLDBLATT AND EUGENE BRAUNWALD \\ WITH THE TECH NICAL ASSISTANCE OF ROBERT M. LEWIS AND LAURENCE KEDES
}

(From the Cardiology Branch, National Heart Institute, Bethesda, Md.)

(Submitted for publication December 1, 1961 ; accepted March 29, 1962)

The circulatory changes that occur during acutely induced hypoxia have been of interest for many years (1-6). It now seems clear that many of the observed responses to this stimulus result from a complex interaction of its direct effects on the heart and the vascular bed and of its indirect effects mediated through nervous, or humoral mechanisms, or both. The present investigation was designed to study the circulatory effects of hypoxia in an experimental preparation in which the responses of the systemic venous bed, the heart, and the systemic arterial bed could be separated. Particular attention was directed to determining the effects of hypoxia on the total systemic venous bed. The potential importance of any changes in venous tone are apparent when it is considered that this segment of the circulation contains the major portion of the systemic blood volume (7). Small changes in the diameter of the veins might be expected to produce large changes in the volume of the venous bed and in the magnitude of the venous return to the heart; any such changes could, in turn, modify the cardiac output and, therefore, the arterial pressure (8-11). In the present investigation the activity of the chemoreceptors, the adrenal glands, and the spleen was also studied, since these organs have been implicated in the circulatory responses to hypoxia (12$18)$.

\section{METHODS}

The experiments were performed on mongrel dogs, weighing 14.7 to $20.3 \mathrm{~kg}$, which were anesthetized with morphine sulfate $(2 \mathrm{mg}$ per $\mathrm{kg}$, s.c.), followed in $30 \mathrm{~min}-$ utes by chloralose ( $45 \mathrm{mg}$ per $\mathrm{kg}$, i.v.), and urethane (450 mg per $\mathrm{kg}$, i.v.). Two basic experimental preparations were employed. Preparation $\mathrm{A}$, used for the experiments subsequently referred to as groups I and II, was similar to that used in previous studies $(10,11)$ and is illustrated in Figure 1. Positive pressure respiration was maintained through a cuffed endotracheal tube until extracorporeal circulation was established. After right thoracotomy and isolation of the femoral vessels, cardiopulmonary bypass was instituted. Blood was drained from the venae cavae and atria through large-bore, rigid cannulae into a rotating disc oxygenator. The blood then passed to a roller pump, through a recording rotameter, and was returned to the dog through a cannula in the femoral artery. All blood entering the right atrium was diverted into the oxygenator and thus the pulmonary circuit was not perfused. The systemic perfusion rate was maintained constant at $100 \mathrm{ml}$ per $\mathrm{kg}$ per minute throughout each experiment. Heparin ( $4 \mathrm{mg}$ per $\mathrm{kg}$ ) was used as the anticoagulant. The blood volume in the oxygenator was kept constant at all times by an electronic sensing device (19) that actuated an auxiliary pump. In order to maintain a constant blood volume in the oxygenator, the auxiliary pump automatically exchanged blood between the oxygenator and a separate blood reservoir. By this technic any change in the volume of this second reservoir reflected an inverse change in the intravascular blood volume of the animal. The volume of blood in the reservoir was determined at 1-minute intervals throughout each experiment, providing minuteto-minute measurement of changes in the intravascular blood volume of the animal. Thus, as has been shown previously $(10,11)$, generalized venoconstriction is accompanied by an increase in venous return to the oxygenator, a decrease in intravascular blood volume, and a reciprocal increase in the volume of blood in the second reservoir. In order to measure venous return more directly, alterations of the intravascular blood volume during hypoxia were prevented in two experiments by modifying the output of the pump. For example, when venous return to the reservoir increased, the pump output was manually increased at a rate sufficient to maintain the volume of the extracorporeal circuit constant. The alterations of systemic perfusion rate were determined and provided a measurement of the changes in venous return.

A direct-writing oscillograph was used to record the following variables simultaneously: a) mean aortic pressure measured by a Statham P23D pressure transducer through a polyethylene catheter inserted through the femoral artery; $b$ ) pressures in the superior and inferior venae cavae measured by two Statham P23A pressure transducers through catheters in the external jugular and femoral veins, respectively; $c$ ) right ventricular contractile force determined with a Walton-Brodie strain gauge arch $(20,21)$ sutured to the right ventricular wall; and 


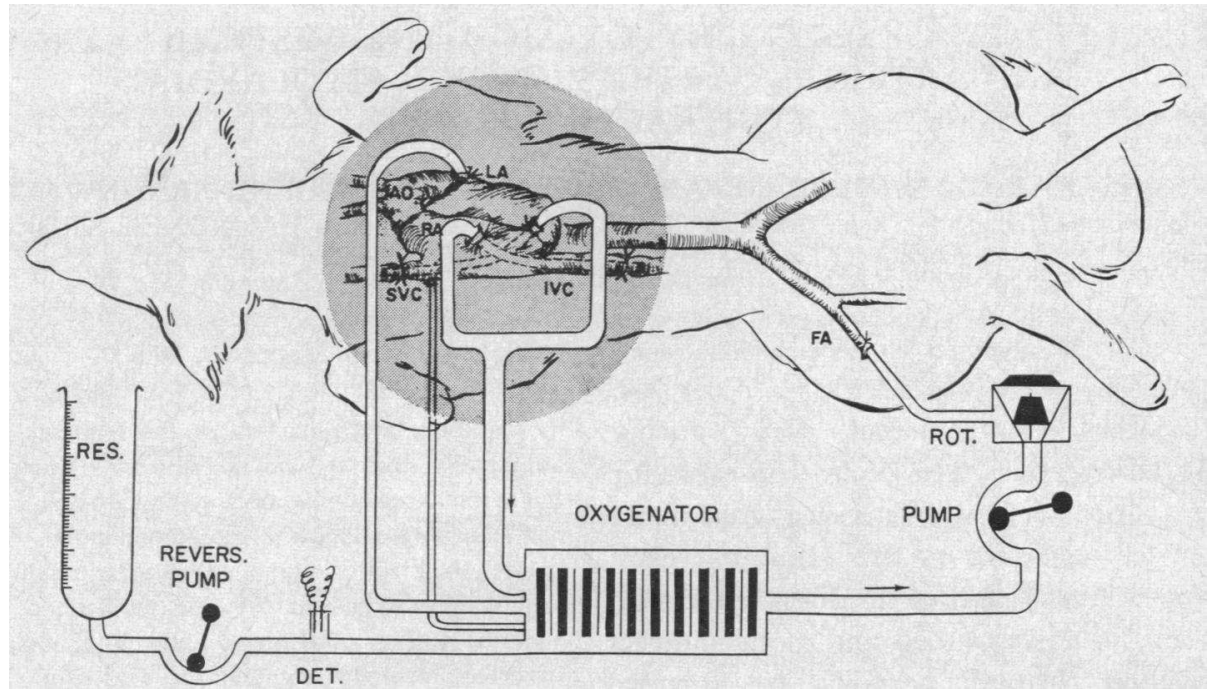

Fig. 1. Schematic diagram of PReparation A. SVC=superior vena cava; IVC $=$ inferior vena cava $; \mathrm{RA}=$ right atrium $; \mathrm{LA}=$ left atrium $; \mathrm{AO}=$ aorta $; \mathrm{FA}=$ femoral artery ; $\mathrm{DET}=$ electronic level detector ; $\mathrm{RES}=$ auxiliary blood reservoir.

d) systemic blood flow measured by means of a ShipleyWilson rotameter $(22)$.

Changes in the oxygen saturation of the arterial blood were induced by modifying the gas mixture supplied to the oxygenator chamber. During the control periods the gas mixture consisted of 98 per cent $\mathrm{O}_{2}: 2$ per cent $\mathrm{CO}_{2}$. Hypoxia was produced by changing to 10 per cent $\mathrm{O}_{2}: 2$ per cent $\mathrm{CO}_{2}: 88$ per cent $\mathrm{N}_{2}$ for periods ranging from 7 to 12 minutes. The oxygen saturation of arterial blood was determined during the control period and at the termination of the experimental period by means of the mano- metric technic of Van Slyke and Neill (23) or a spectrophotometric method (24).

Hypoxia was induced in 17 animals prepared as described above. Four of these had undergone splenectomy and bilateral adrenalectomy 3 to 4 weeks prior to study and were then maintained on parenteral cortisone. Six of the dogs were studied after chemoreceptor denervation, carried out as described below. The remaining seven dogs had not undergone any operative procedure other than that for cardiopulmonary bypass and will be referred to as "intact" animals. Succinylcholine was ad-

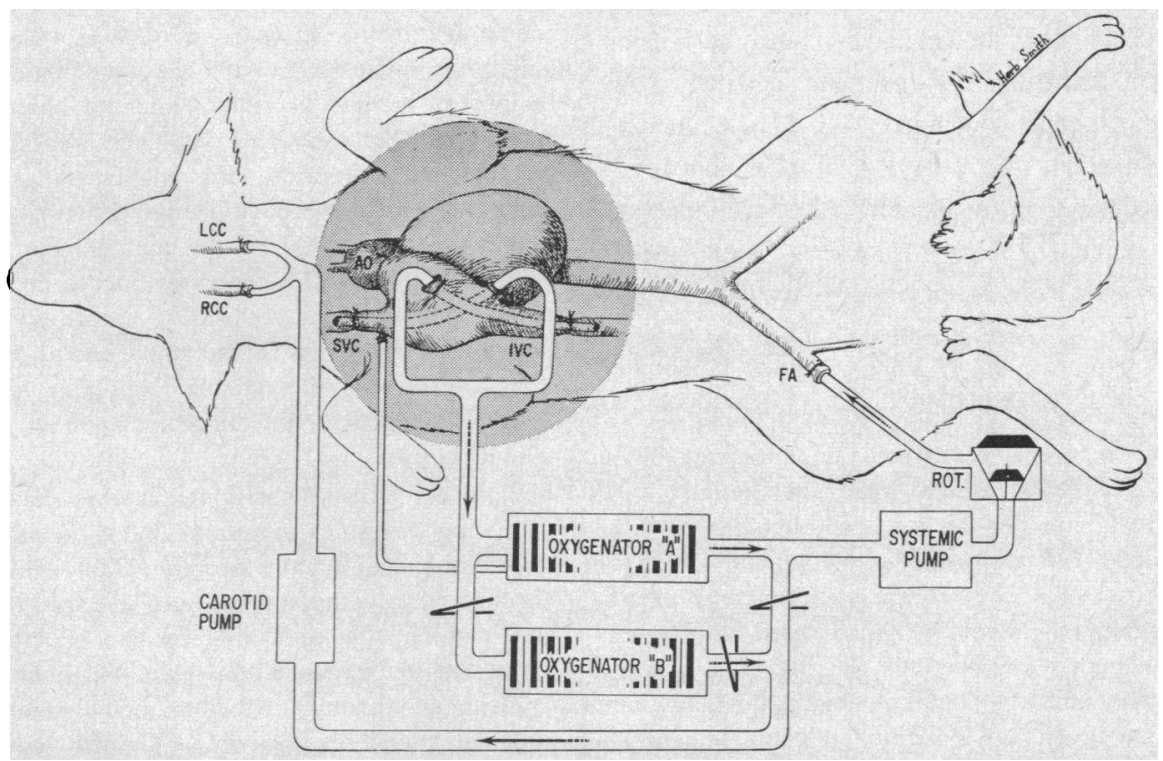

Fig. 2. Schematic diagram of preparation B. LCC and RCC refer to the left and right common carotid arteries. Other abbreviations same as in Figure 1. 


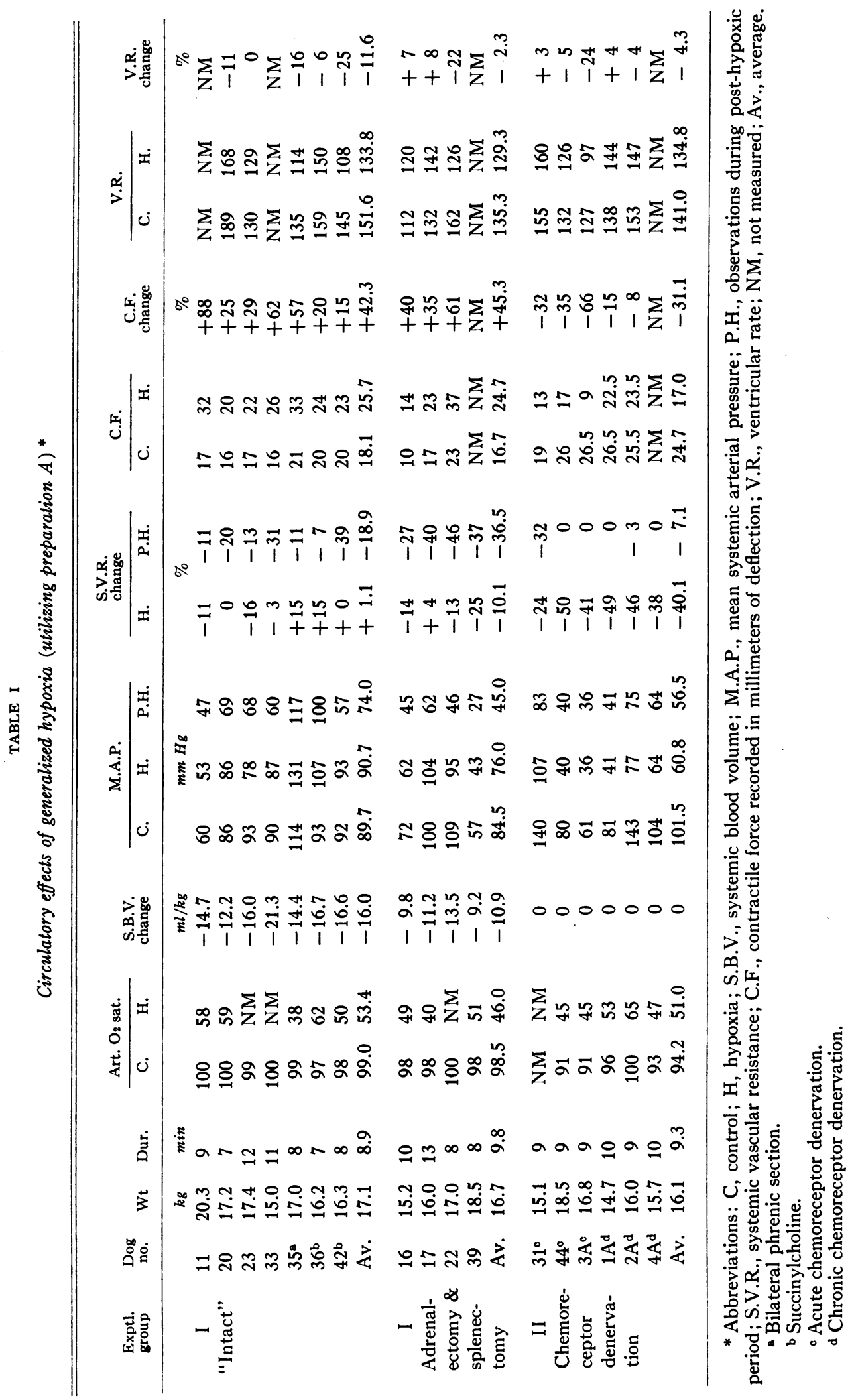




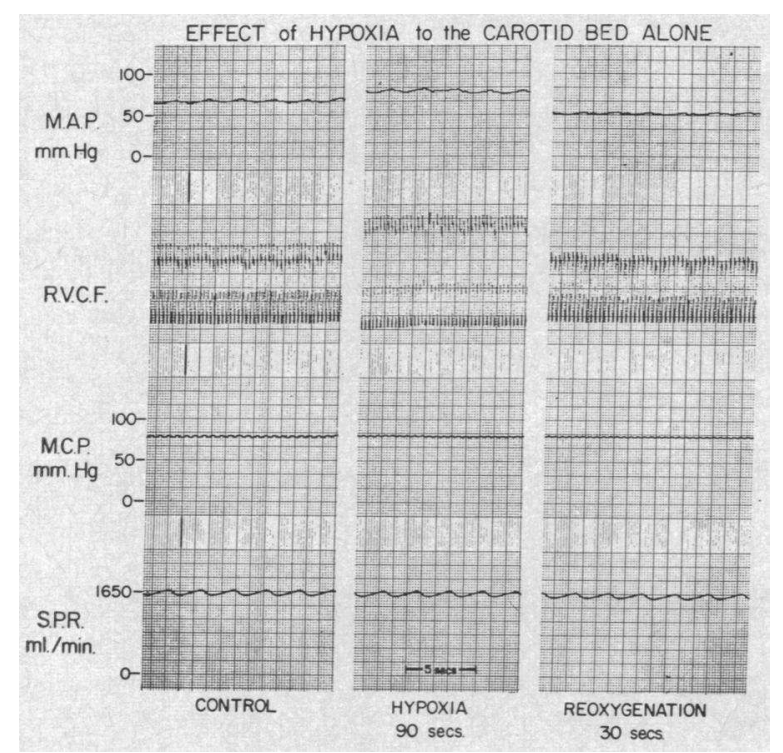

FIG. 3. M.A.P. $=$ mean aortic pressure. R.V.C.F. $=$ right ventricular contractile force; M.C.P. $=$ mean carotid pressure; S.P.R. = systemic perfusion rate.

ministered to two of these animals in order to produce skeletal muscle paralysis, and bilateral phrenic nerve section was performed in one animal in the intact group.

Denervation of the carotid chemoreceptors consisted of bilateral resection of a portion of the carotid arterial tree between points that were $1 \mathrm{~cm}$ proximal and distal to the carotid bifurcation; this resection included removal of the carotid body and section of the sinus nerve. In three dogs the carotid denervations were carried out immediately before studying the effects of hypoxia and in three others the denervations were carried out 5 to 12 days before the experiment. The aortic chemoreceptors were denervated by sectioning the vagus nerves in the neck on the day of the experiment. Denervation of the carotid and aortic baroreceptors necessarily accompanied denervation of the chemoreceptors.

In preparation $\mathrm{B}$, a double perfusion system, schematically illustrated in Figure 2, was employed in four dogs (groups III and IV) in order to separate the reflex effects of hypoxia from the direct, local effects of this stimulus. Blood was drained from the venae cavae into oxygenator A, which was supplied either with 98 per cent $\mathrm{O}_{2}: 2$ per cent $\mathrm{CO}_{2}$, or with 10 per cent $\mathrm{O}_{2}: 2$ per cent $\mathrm{CO}_{2}: 88$ per cent $\mathrm{N}_{2}$. Blood was pumped from this oxygenator into the femoral artery, as in preparation $\mathrm{A}$. In addition, the two common carotid arteries were isolated and cannulated, and perfused by a second pump, from oxygenator $A$ or $B$; the latter was supplied with 5 , 10 , or 98 per cent $\mathrm{O}_{2}: 2$ per cent $\mathrm{CO}_{2}$ and the remainder nitrogen. Bilateral cervical vagotomy was performed in all of these animals in order to denervate the aortic chemoreceptors. With this preparation it was possible to vary independently the oxygen saturation of the blood perfusing the carotid arteries and the remainder of the systemic arterial bed. The perfusion pressure in both carotid arteries was kept constant by varying the output of the carotid perfusion pump slightly, and in some of these experiments heart rate was controlled by means of electrical stimulation of the right ventricle.

\section{RESULTS}

During the control periods for experimental groups I and II the arterial oxygen saturation ranged from 91 to 100 per cent with an average value of 97.4. At the termination of the period of hypoxia the saturation ranged from 38 to 65 per cent with an average value of 50.1 .

A. Intravascular blood volume. Hypoxia resulted in an increase in venous return and a consequent decline in systemic blood volume in all 11 dogs with intact chemoreceptors (group I). The decrease in blood volume ranged from 12.2 to 21.3 $\mathrm{ml}$ per $\mathrm{kg}$ (average, 16.0) in the seven "intact" dogs (including the two animals which had received succinylcholine and the one animal in which the phrenic nerves had been sectioned). In the four dogs in which bilateral adrenalectomy and splenectomy had been performed, the blood volume decreased by 9.2 to $13.5 \mathrm{ml}$ per $\mathrm{kg}$ (average, 10.9). Hypoxia did not result in any change in venous return or in intravascular blood volume in the six dogs in group II which had been subjected previously to denervation of the carotid and aortic chemoreceptors (Table I).

$B$. Venous return. In order to maintain constant the volume of the extracorporeal circuit, and therefore of the intravascular compartment, during the hypoxia period, it was necessary to increase the output of the pump by 16 and 24 per cent of control values in two dogs with intact chemoreceptors which were studied in this manner.

C. Mean aortic pressure. There was considerable variation of the response of mean aortic pressure to generalized hypoxia in the experiments of group I. In the intact animals these changes ranged from +15 to -16 per cent of control values, with a mean change of +1.1 (Table $I$ ). In the four dogs in which adrenalectomy and splenectomy had been performed, mean aortic pressure during hypoxia varied from +4 to -25 per cent (average, -10.1 ) of control values. All six dogs in group II, in which the chemoreceptors had been denervated, showed a fall in mean aortic pressure ranging from 24 to 50 per cent (average. 40.1 ; Table I). 






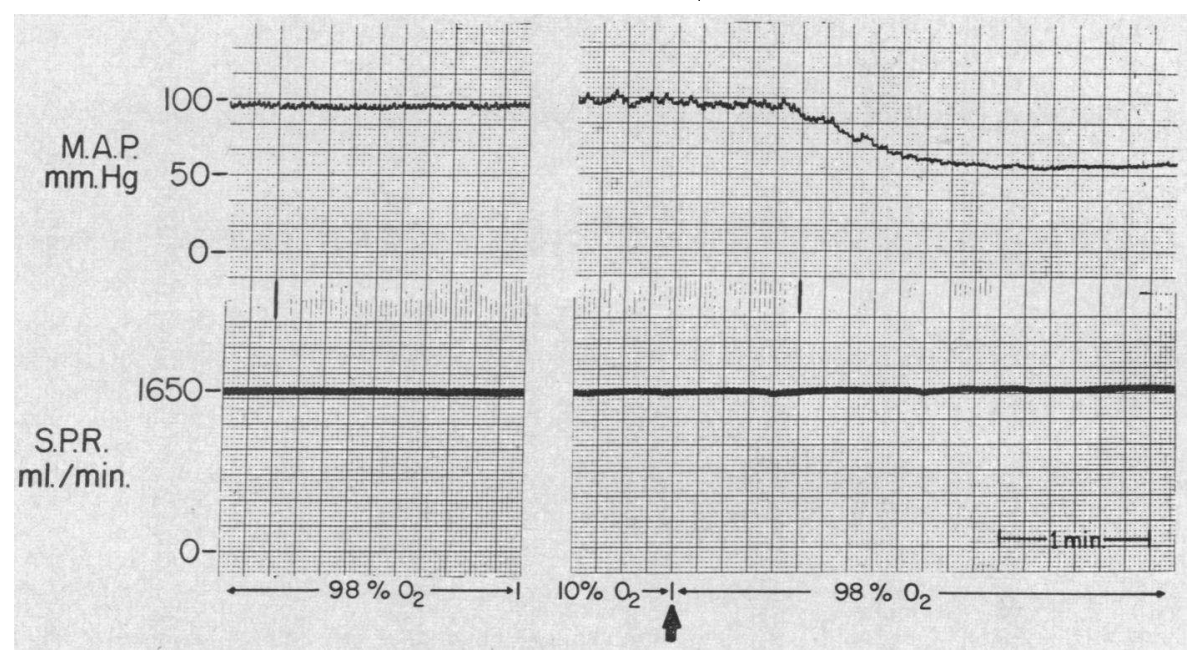

Fig. 4. Post-hypoxic vasodilatation. Abbreviations same as in Figure 3 . The vertical arrow indicates the instant at which the gas supply to the oxygenator was changed to $98 \% \mathrm{O}_{2}$ after 8 minutes of $10 \% \mathrm{O}_{2}$.

In preparation $B$, poorly oxygenated blood ( saturation 21 to 71 per cent; average, 50.0) was delivered to the carotid arteries, while the remainder of the systemic vascular bed was perfused with oxygenated blood on twelve occasions in four dogs in group III. An increase in arterial pressure occurred in eleven of these trials (Figure 3 ) and a decrease $(-4$ per cent) in one. The average change for the twelve trials was an elevation of 15.4 per cent above control levels (Table II). In two dogs in group IV the carotid arteries were perfused with oxygenated blood, while poorly oxygenated blood was delivered to the remainder of the systemic circulation. In both instances a decline in systemic vascular resistance, 34 and 22 per cent of control levels, occurred (Table II).

D. Post-hypoxic dilatation. Within 1 minute after reinstitution of the 98 per cent $\mathrm{O}_{2}: 2$ per cent $\mathrm{CO}_{2}$ mixture to the oxygenator, a brief but striking decline in mean aortic pressure occurred in the dogs without chemoreceptor denervation (group I; Figure 4). In the intact dogs this decline ranged from 7 to 39 per cent (average, 18.9) of the pressure existing just before the reinstitution of 98 per cent $\mathrm{O}_{2}$. In the animals which had been subjected to adrenalectomy and splenectomy, the decline ranged from 27 to 46 per cent (average, 37.5 ) of the pressure existing just before reoxygenation. Five of the six animals in group II, in which the chemoreceptors had been denervated, exhibited no post-hypoxic dilatation, whereas the sixth animal demonstrated a 32 per cent fall in mean aortic pressure with reoxygenation (Table I).

E. Myocardial contractile force. An increase in right ventricular contractile force occurred in all animals in group I, in which generalized hypoxia was induced in the presence of intact chemoreceptors. The changes in contractile force in the intact dogs ranged from +15 to +88 per cent (average, 42 ; Table I). In the three dogs in which adrenalectomy and splenectomy had previously been performed and in which contractile force was measured, this parameter increased 35, 41, and 61 per cent (average, +45.3 ). Changes in contractile force during generalized hypoxia were measured in five of the six dogs in group II with chemoreceptor denervation, and a decline ranging from 8 to 66 per cent (average, 31.1) of control levels was observed (Table I).

In preparation $\mathrm{B}$, myocardial contractile force rose by 3 to 43 per cent of control levels in eleven of twelve trials in the four dogs in group III in which poorly oxygenated blood perfused the carotid arteries, while oxygenated blood was delivered to the heart and the remainder of the systemic circuit (Figure 3, Table II). In the other trial contractile force declined by 9 per cent of control. The average change for the twelve experiments was an increase of contractile force which was 13.6 per cent of control. In both dogs in group IV in which the carotid arteries were perfused with 
oxygenated blood, while poorly oxygenated blood was delivered to the remainder of the systemic circulation, myocardial contractile force fell by 9 and 28 per cent of control levels (Table II).

F. Heart rate. When poorly oxygenated blood was delivered to the entire systemic circulation (group I) ventricular rate changed by 0 to -25 per cent (average, -11.6 ) of control in the five intact animals, from +8 to -22 per cent (average, -2.3 ) in the three animals in which adrenalectomy and splenectomy had previously been performed, and from +4 to -25 per cent (average, -4.3 ) in animals with denervated chemoreceptors (Table I).

\section{DISCUSSION}

The reactivity of the preparation employed in the present experiments was of necessity compromised to some extent by the general anesthesia and the extensive operative procedure. These interventions were dictated, however, by the major goal of this study, which was to separate the effects of hypoxia on the heart and the venous and arterial systems. Blood $\mathrm{pH}, \mathrm{pCO}_{2}$, lactic acid, and a host of other biochemical variables were not determined in these experiments, and the possibility certainly exists that many of these were altered by anesthesia, operation, and the use of cardiopulmonary bypass. Furthermore, the induction of hypoxia may well have resulted in further changes of $\mathrm{pH}$, $\mathrm{pCO}_{2}$, and so forth. The possibility has not been excluded that some of the circulatory alterations produced by hypoxia may be related to these secondary biochemical changes.

A. Intravascular blood volume and venous return. It has been demonstrated previously that the entire systemic venous bed takes part in the reflex response to stimulation of carotid (10) and intracardiac baroreceptors (11), and participation of the venous system in the response to hypoxia and asphyxia has been suggested $(9,25,26)$.

In all of the experiments in which the chemoreceptor and baroreceptor reflex arc was intact, hypoxia resulted in an increase in venous return, and a decrease in systemic blood volume approximating 20 per cent of the total blood volume and 25 per cent of the extracardiopulmonary blood volume of the dog. Since the volume of the postcapillary bed comprises about 75 per cent of the animal's systemic blood volume (7) and the observed changes in blood volume were relatively large, it seems reasonable to conclude that the major change in volume occurred in the postcapillary bed and resulted from venoconstriction. This assumption is supported by the occurrence of only relatively minor changes in systemic vascular resistance during the hypoxic period, which suggests that little change occurred in the volume of blood contained in the precapillary bed. It is well recognized that a sphincter mechanism exists in the hepatic veins of the $\operatorname{dog}(27)$, and the possibility that dilatation of these sphincters may have contributed to the increase in venous return has not been excluded. The changes in pump output, which were neces-

TABLE 111

A summary of the effects of acute hypoxia in animal groups $I-I V$

\begin{tabular}{|c|c|c|c|c|c|}
\hline & Group & I & II & III & IV \\
\hline \multirow[t]{4}{*}{$\begin{array}{c}\text { Experimental } \\
\text { conditions }\end{array}$} & $\begin{array}{l}\text { Carotid chemo- } \\
\text { receptors }\end{array}$ & Intact & Denerv & Intact & Intact \\
\hline & $\begin{array}{l}\text { Aortic chemo- } \\
\text { receptors }\end{array}$ & Intact & Denerv & Denerv & Denerv \\
\hline & $\begin{array}{c}\text { Carotid arterial } \\
\text { bed }\end{array}$ & Hypoxic & Hypoxic & Hypoxic & Eupoxic \\
\hline & $\begin{array}{l}\text { Systemic vascu- } \\
\text { lar bed }\end{array}$ & Hypoxic & Hypoxic & Eupoxic & Hypoxic \\
\hline \multirow{5}{*}{$\begin{array}{l}\text { Experimental } \\
\text { results }\end{array}$} & Venous return & $\uparrow$ & No change & Not measured & Not measured \\
\hline & $\begin{array}{l}\text { Systemic vascu- } \\
\text { lar resistance }\end{array}$ & Variable & $\downarrow$ & $\uparrow$ & $\downarrow$ \\
\hline & $\begin{array}{c}\text { Post-anoxic } \\
\text { arteriolar } \\
\text { dilatation }\end{array}$ & Present & Absent* & Variable & Absent \\
\hline & $\begin{array}{l}\text { Myocardial con- } \\
\text { tractile force }\end{array}$ & $\uparrow$ & $\downarrow$ & $\uparrow$ & $\downarrow$ \\
\hline & Heart rate & $\downarrow$ & Variable & Variable & No change \\
\hline
\end{tabular}

* Absent in 5 of 6 . 
sary to prevent alterations in the volume of the systemic circuit during hypoxia, are similar to the changes in cardiac output that would have occurred had the heart responded to changes in venous return alone. These observations indicate that, in the absence of any direct effect upon the heart itself, the cardiac output would increase during hypoxia, as a result of the increase in venous return. Since the augmentation of venous return induced by hypoxia was completely eliminated by interruption of the chemoreceptor reflex arc, it is concluded that this augmentation observed in the intact animals resulted from stimulation of the carotid body, or aortic chemoreceptors, or both (Table III). Bilateral adrenalectomy and splenectomy tended to diminish the decrease in blood volume that occurred during hypoxia, although there was considerable overlap among the values observed. These findings suggest that the release of catecholamines from the adrenal medulla, or the contraction of the spleen, or both, play a significant, but not a major, role in the displacement of blood from the systemic vascular bed during hypoxia. The observation that the decrease in systemic blood volume induced by hypoxia was not diminished by section of the phrenic nerves or by skeletal muscle paralysis indicates that in these open-chest dogs increased activity of the thoracic pump induced by hypoxia was not responsible for the augmentation of venous return.

$B$. Mean aortic pressure. Any change in mean aortic pressure occurring in those experiments in which blood flow from the pump into the systemic vascular bed was maintained constant reflects a parallel change in systemic vascular resistance (28). When poorly oxygenated blood was delivered to the entire systemic vascular bed, the effect on systemic vascular resistance of the intact dogs (group I) was not marked or consistent. However, after denervation of the chemoreceptors (group II), a significant decrease in vascular resistance was observed. Resistance also declined in the vagotomized dogs in which the systemic circuit was perfused with poorly oxygenated blood, while the carotid arteries were perfused with oxygenated blood (group IV). On the other hand, when oxygenated blood perfused the systemic vascular bed, while poorly oxygenated blood was delivered to the carotid arteries (group III), an elevation of systemic vascular resistance was usually noted. These results, summarized in Table III, indicate that the direct effect of hypoxia is to produce a net arteriolar dilatation but that this response is opposed by the arteriolar constriction which is mediated by the chemoreceptor reflex arc. The effects in the intact dogs represent the summation of these opposite influences. With the preparation employed, no information on the effect of hypoxia on specific arterial beds could be obtained, but the net effect on the total systemic vascular bed was determined. It is possible that the magnitude and even the direction of change may have varied in different beds. The vascular resistance tended to decline to a greater extent in the adrenalectomized dogs than in the intact dogs. This observation suggests that the adrenal gland contributes to the counteraction of the direct vasodilatory effects of hypoxia on the arteriolar bed.

C. Post-hypoxic dilatation. The sudden, brief decline in vascular resistance after cessation of hypoxia, "post-hypoxic dilatation," has been observed previously by a number of investigators (29-31), but the mechanism responsible for it has been disputed. Litwin, Dil and Aviado believe that this phenomenon is neurogenic in origin, but not dependent upon an intact chemoreceptor reflex arc (31). In the present experiments this phenomenon was consistently observed in the dogs with intact aortic and carotid chemoreceptors (group I), and in six of twelve experiments in vagotomized dogs in which the carotid chemoreceptors were intact and perfused with poorly oxygenated blood. However, it was observed in only one of six dogs in which both groups of receptors had been denervated (group II), and it was absent in all experiments after systemic hypoxia had been produced in animals in which the carotid chemoreceptors were not exposed to hypoxia and the aortic receptors had been denervated (group IV; Table III). These data support the view (31) that posthypoxic arteriolar dilatation is neurogenic in origin, but they suggest that intact chemoreceptors must be stimulated in order for this phenomenon to occur. It is suggested that post-hypoxic dilatation results from the sudden withdrawal of reflexly induced arteriolar constriction, while the direct vasodilatory effect of hypoxia persists for a somewhat longer period. However, the possibility has not been excluded that maximal vasodilatation occurring prior to the cessation of hypoxia pre- 
vented the occurrence of postanoxic arteriolar dilatation in those experiments in which this phenomenon was not observed.

D. Myocardial contractile force. It is well established from animal experiments (2) as well as from observations on unanesthetized man (4, 32) that moderate degrees of hypoxia are consistently associated with an increase of cardiac output. Changes in cardiac output, however, do not necessarily reflect alterations in myocardial contractile force, since variations in venous return, systemic resistance, and heart rate can also profoundly modify cardiac output $(33,34)$. Woods and Richardson (35) demonstrated that marked increases in myocardial contractile force occurred when vagotomized open-chest dogs were exposed to 100 per cent nitrogen. While adrenalectomy did not modify this response, total sympathetic blockade reduced the anoxia-induced augmentation of contractile force. Honig and Tenney (12), utilizing a ballistocardiograph, showed that an increase in cardiac force which was not dependent upon the presence of the adrenal glands occurred during hypoxia. Downing, Remensnyder and Mitchell (36) recently demonstrated that an elevation of the curves of left ventricular function occurred during generalized hypoxia, but that curves of ventricular function were unchanged or became depressed when the hypoxia was confined to the carotid chemoreceptors.

In the present experiments increase in contractile force occurred during generalized hypoxia when the chemoreceptors were intact (group I), regardless of the presence of the adrenal glands. An increase in contractile force was also observed when the hypoxia was limited to the carotid perfusion circuit, while oxygenated blood perfused the heart and the remainder of the systemic circulation (group III). Contractile force was augmented in experiments in which changes in heart rate occurred, as well as in those in which rate was held constant. In the dogs in which the chemoreceptors had been denervated, generalized hypoxia reduced contractile force (group II). A decrease in myocardial contractile force was also observed in the dogs with intact carotid receptors, in which only the carotid perfusion circuit received oxygenated blood (group IV). These data (Table III) are consistent with the view that the augmentation of myocardial contractile force that occurs during hypoxia is reflex in origin, and that the carotid and aortic chemoreceptors form the afferent limb of this reflex arc. However, the direct effect of hypoxia on the myocardium is to depress its contractility, a view which is also supported by the observation of Gremels and Starling on the heartlung preparation (37) and of Sands and DeGraff in intact anesthetized dogs (38). Our data are not consonant with the hypothesis of Baugh, Cornett and Hatcher (14) nor of Nahas, Mather, Wargo and Adams (39), who have suggested that the cardiac sympathetic nerves do not play a major role in the cardiac response to hypoxia. but who considered circulating catecholamines from the adrenal medulla to be of prime importance. There seems to be little doubt that adrenal catecholamine release can occur during hypoxia. Fowler, Shabetai and Holmes (16) found that norepinephrine-like substances increased in adrenal venous blood in dogs whose arterial oxygen saturations were lowered to between 33 and 59 per cent. Ludemann, Filbert and Cornblath (17), however, using a fluorometric assay technic, could find no rise in the epinephrine content of peripheral plasma in asphyxiated dogs, unless the arterial oxygen saturation fell below 42 per cent. The data in Table I show that hypoxia can produce a large increase in myocardial contractile force in the absence of both adrenal glands. Thus, as with the effects on the systemic arterial bed, the response of myocardial contractile force to hypoxia observed in the intact animal results from a complex interaction of reflex and direct effects.

It should be pointed out that in the present experiments the hypoxic stimulus was applied either to the entire central nervous system (groups I and II) or to a portion of it (groups III and IV). It has recently been suggested that exposure of the central nervous system to hypoxic blood may result in sympathetic stimulation of the heart (36). This hypothesis could not be critically evaluated in our experiments, since hypoxia of the central nervous system alone was not induced; however. since generalized hypoxia always resulted in a depression of contractile force in the chemoreceptor-denervated animals (group II), it seems unlikely that the cardiac augmentation resulting from direct hypoxic stimulation of the central nervous system could be a powerful effect with the degree 
of arterial unsaturation employed in the present experiments.

E. Heart rate. Systemic hypoxia has been shown to elevate the heart rate in almost all mammalian species that have been studied $(2,4)$, but hypoxia of the isolated carotid body slows the heart rate $(36,40,41)$. Although the explanation for this difference is not clear, "pulmonary reflexes" have been mentioned as a possible cause for the increase in rate observed in intact animals (40). The results obtained in these experiments are consistent with this view, since a decrease in heart rate occurred in the intact dogs during hypoxia (group I), while no consistent changes were observed after chemoreceptor denervation (group II). Although hypoxia produced some respiratory movements in those dogs which had not received succinylcholine, their lungs remained collapsed throughout the control and experimental periods. It therefore appears possible that the slight bradycardia that was observed in group I was related to stimulation of the chemoreceptors in the absence of the antagonizing pulmonary reflexes.

\section{SUMM ARY}

The circulatory effects of lowering arterial oxygen saturation were studied in dogs in a manner permitting the independent assessment of the reactions of the arterial vessels, the venous vessels, and the myocardium to hypoxia. In addition, the role of the chemoreceptors in the mediation of these responses was investigated by hemodynamically isolating or denervating these structures.

Generalized systemic hypoxia resulted in an increase in venous return and a striking decrease in systemic blood volume. These changes were interpreted to be due to systemic venoconstriction. Since these effects could be prevented by chemoreceptor denervation, it was concluded that they were mediated by the chemoreceptor reflex arc. An increase in systemic vascular resistance occurred when hypoxemia was localized to the carotid arterial bed, but a decline in systemic vascular resistance was observed when the entire systemic vascular bed was made hypoxic and the chemoreceptors denervated or perfused with oxygenated blood. These results indicate that the direct effect of hypoxia is to produce net arteriolar dilatation but that this response is opposed by the ar- teriolar constriction which is mediated through the chemoreceptor reflex arc. Posthypoxic dilatation occurred only in animals in which intact chemoreceptors were stimulated by hypoxia; these experiments support the view that this response is neurogenic in origin and suggest that it requires an intact chemoreceptor reflex arc.

Myocardial contractile force increased when intact chemoreceptors were perfused with hypoxic blood, regardless of the saturation of blood perfusing the heart. Myocardial contractile force decreased, however, when poorly oxygenated blood perfused the heart and when the chemoreceptors were either denervated or perfused with well oxygenated blood. It therefore appears that the augmentation of myocardial contractile force that occurs during generalized hypoxia is dependent upon an intact chemoreceptor reflex arc that opposes the direct myocardial depressant effects of hypoxia.

\section{REFERENCES}

1. Heymans, C. and Neil, E. Reflexogenic Areas of the Cardiovascular System. Boston, Little, Brown, 1958.

2. Korner, P. I. Circulatory adaptations in hypoxia. Physiol. Rev. 1959, 39, 687.

3. McDowall, R. J. S. The Control of the Circulation of the Blood, 2 vols. London, William Dawson, 1956.

4. Fishman, A. P. Respiratory gases in the regulation of the pulmonary circulation. Physiol. Rev. 1961, 41, 214.

5. Harrison, T. R., Blalock, A., Pilcher, C., and Wilson, C. P. The regulation of circulation. VIII. The relative importance of nervous, endocrine and vascular regulation in the response of the cardiac output to anoxemia. Amer. J. Physiol. 1927, 83, 284.

6. Gorlin, R., and Lewis, B. M. Circulatory adjustments to hypoxia in dogs. J. appl. Physiol. 1954, $7,180$.

7. Green, H. D. in Medical Physics, O. Glasser, Ed. Chicago, Year Book Publishers, 1944, vol. 1, p. 210.

8. Bartelstone, H. J. Role of the veins in venous return. Circulat. Res. 1960, 8, 1059 .

9. Alexander, R. S. The participation of the venomotor system in pressor reflexes. Circulat. Res. 1954, 2, 405.

10. Ross, J., Jr., Frahm, C. J., and Braunwald, E. Influence of carotid baroreceptors and vasoactive drugs on systemic vascular volume and venous distensibility. Circulat. Res. 1961, 9, 75. 
11. Ross, J., Jr., Frahm, C. J., and Braunwald, E. The influence of intracardiac baroreceptors on venous return, systemic vascular volume and peripheral resistance. J. clin. Invest. 1961, 40, 563.

12. Honig, C. R., and Tenney, S. M. Determinants of the circulatory response to hypoxia and hypercapnea. Amer. Heart J. 1957, 53, 687.

13. Houssay, B. A., and Molinelli, E. A. Adrenal secretion produced by asphyxia. Amer. J. Physiol. 1926, 76, 538.

14. Baugh, C. W., Cornett, R. W., and Hatcher, J. D. The adrenal gland and the cardiovascular changes in acute anoxic anoxia in dogs. Circulat. Res. 1959, 7, 513.

15. Celander, $O$. The range of control exercised by the sympatho-adrenal system. Acta physiol. scand. 1954, 32, suppl. 116, 1.

16. Fowler, N. O., Shabetai, R., and Holmes, J. C. Adrenal medullary secretion during hypoxia, bleeding, and rapid intravenous infusion. Circulat. Res. 1961, 9, 427.

17. Ludemann, H. H., Filbert, M. G., and Cornblath, M. Application of a fluorometric method for adrenaline-like substances in peripheral plasma. J. appl. Physiol. 1955, 8, 59.

18. Schmidt, C. F., and Comroe, J. H., Jr. Functions of the carotid and aortic bodies. Physiol. Rev. 1940, $20,115$.

19. Waldhausen, J. A., Ross, J., Jr., Lombardo, C. R., Cooper, T., Gilbert, J. W., and Morrow, A. G. Flow and volume regulation during cardiopulmonary bypass: The use of an electromagnetic flowmeter and a device for the automatic control of oxygenator volume. Trans. Amer. Soc. artif. intern. Organs 1959, 5, 172.

20. Boniface, K. J., Brodie, O. J., and Walton, R. P. Resistance strain gauge arches for direct measurement of heart contractile force in animals. Proc. Soc. exp. Biol. (N.Y.) 1953, 84, 263.

21. Cotton, M. DeV., and Bay, E. Direct measurement of changes in cardiac contractile force. Relationship of such measurements to stroke work, isometric pressure gradient and other parameters of cardiac function. Amer. J. Physiol. 1956, 187, 122.

22. Shipley, R. E., and Wilson, C. An improved recording rotameter. Proc. Soc. exp. Biol. (N.Y.) 1951, 78, 724.

23. Van Slyke, D. D., and Neill, J. M. The determination of gases in blood and other solutions by vacuum extraction and manometric measurement. I. J. biol. Chem. 1924, 61, 523.

24. Wyeth, J., Ecker, P., and Polis, B. D. Spectrophotometric determination of blood oxygen saturation. Document no. NADC-MA-5408, U. S. Air Development Center, Johnsville, Pa., July 16, 1954.

25. Eckstein, J. W., and Horsley, A. W. Effects of hypoxia on peripheral venous tone in man. J. Lab. clin. Med. 1960, 56, 847.

26. Rashkind, W. J., Lewis, D. H., Henderson, J. B., Heiman, D. F., and Dietrick, R. B. Venous return as affected by cardiac output and total peripheral resistance. Amer. J. Physiol. 1953, 175, 415.

27. Ross, J., Jr., Braunwald, E., and Waldhausen, J. A. Studies on digitalis. II. Extracardiac effects on venous return and on the capacity of the peripheral vascular bed. J. clin. Invest. 1960, 39, 937.

28. Ross, J., Jr., Waldhausen, J. A., and Braunwald, E. Studies on digitalis. I. Direct effects on peripheral vascular resistance. J. clin. Invest. 1960, 39, 930.

29. Bernthal, T. Chemo-reflex control of vascular reactions through the carotid body. Amer. J. Physiol. 1938, 121, 1.

30. Bernthal, T., and Schwind, F. J. A comparison in intestine and leg of the reflex vascular response to carotid-aortic chemoreceptor stimulation. Amer. J. Physiol. 1945, 143, 361.

31. Litwin, J., Dil, A. H., and Aviado, D. M. Effects of anoxia on the vascular resistance of the dog's hind limb. Circulat. Res. 1960, 8, 585.

32. Chidsey, C. A., Frye, R. L., Kahler, R. L., and Braunwald, $\mathrm{E}$. Influence of syrosingopine on the cardiovascular response to acute hypoxemia and exercise. Circulat. Res. 1961, 9, 989.

33. Goldberg, L. I., Bloodwell, R. D., Braunwald, E., and Morrow, A. G. The direct effects of norepinephrine, epinephrine, and methoxamine on myocardial contractile force in man. Circulation 1960, 22, 1125.

34. Braunwald, E., Bloodwell, R. D., Goldberg, L. I., and Morrow, A. G. Studies on digitalis. IV. Observations in man on the effects of digitalis preparations on the contractility of the non-failing heart and on total vascular resistance. J. clin. Invest. 1961, 40, 52.

35. Woods, E. F., and Richardson, J. A. Effects of acute anoxia on cardiac contractility. Amer. J. Physiol. 1959, 196, 203.

36. Downing, S. E., Remensnyder, J. P., and Mitchell, J. H. Cardiovascular responses to hypoxic stimulation of the carotid bodies. Circulat. Res. 1962, $10,676$.

37. Gremels, H., and Starling, E. H. On the influence of hydrogen ion concentration and of anoxemia upon the heart volume. J. Physiol. (Lond.) 1926, 61, 297.

38. Sands, J., and DeGraff, A. C. The effects of progressive anoxemia on the heart and circulation. Amer. J. Physiol. 1925, 74, 416.

39. Nahas, G. G., Mather, G. W., Wargo, J. D. M., and Adams, W. L. Influence of acute hypoxia on sympathectomized and adrenalectomized dogs. Amer. J. Physiol. 1954, 177, 13.

40. Daly, M. DeB., and Scott, M. J. The effects of stimulation of the carotid body chemoreceptors on heart rate in the dog. J. Physiol. (Lond.) 1958, 144, 148.

41. Daly, M. DeB., and Scott, M. J. The effect of hypoxia on the heart rate of the dog with special reference to the contribution of the carotid chemoreceptors. J. Physiol. (Lond.) 1959, 145, 440. 